\title{
NEOLIBERALISMO E O SISTEMA DA DÍVIDA: COMO A FINANCEIRIZAÇÃO DA DÍVIDA PÚBLICA PODE AFETAR OS DIREITOS PREVIDENCIÁRIOS NO ESTADO DE PERNAMBUCO ${ }^{1}$
}

\author{
NEOLIBERALISM AND THE DEBT SYSTEM: HOW THE FINANCIALIZATION OF \\ PUBLIC DEBT CAN AFFECT SOCIAL SECURITY RIGHTS IN THE STATE OF \\ PERNAMBUCO
}

\author{
Aline Araújo de Albuquerque Melo* \\ Juliana Teixeira Esteves**
}

\section{RESUMO}

Analisando dados disponíveis no site do Banco Mundial, desde 1979 o estado de Pernambuco tomou quinze empréstimos para projetos de desenvolvimento social. Foram identificadas nos contratos críticas tecidas pelo Banco Mundial ao sistema previdenciário brasileiro e estadual, fazendo referências à necessidade de uma reforma previdenciária. As dívidas externas do Estado de Pernambuco cresceram continuamente, sendo seu pagamento obrigação fiscal prevista anualmente pela Lei Orçamentária Anual. A teia de dívidas acarreta a desregulamentação das condições de trabalho e flexibilização dos direitos sociais, ou seja, pela guinada das prioridades na alocação de recursos públicos: do bem-estar social para a lubrificação da engrenagem neoliberal, mantendo em movimento o moinho da financeirização. Em 2019 o Estado de Pernambuco aprovou a Lei Complementar $n^{\circ} 423$, criando um fundo de capitalização complementar para novos servidores sem deixar evidenciado se será público ou se poderá vir a ser privado. As reformas no âmbito previdenciário são interessantes para as instituições financeiras, visto que o dinheiro da previdência é rentável e seguro, descontado mensalmente do salário dos(as) trabalhadores(as). Mas para que o sistema financeiro tenha acesso à essa poupança, e obtenha rendimentos a partir dela, é necessário privatizar os direitos sociais.

Palavras-chave: dívidas públicas; reforma previdenciária; neoliberalismo; financeirização.

\section{ABSTRACT}

Analyzing data available on the World Bank website, since 1979 the state of Pernambuco has borrowed fifteen loans for social development projects. Criticisms of the Brazilian state pension system were identified in the contracts made by the World Bank, making references to the need for a social security reform. The external debts of Pernambuco grew continuously, and their payment is a fiscal obligation provided for annually by the Lei Orçamentária Anual. The debt system results in deregulation of working conditions and the flexibilization of social rights, happens the shift in priorities in the allocation of public resources: from social welfare to the lubrication of the neoliberal gearing, keeping the financialization wheel in motion. In 2019, the State of Pernambuco approved Lei Complementar $n^{\circ} 423$, creating a complementary capitalization fund for new employees without making it clear whether the funds would be public or private. Social security reforms are interesting for financial institutions, as the pension money is profitable and safe, deducted monthly from the workers' wages. But for the financial system to have access

* Graduanda em Direito - CCJ - UFPE. E-mail: aline.araujom@ufpe.br

**Docente/pesquisador do Depto de Direito Público Especializado - CCJ - UFPE. E-mail: juliana.esteves@ufpe.br.

${ }^{1}$ Pesquisa desenvolvida em Iniciação Científica e com apoio do CNPQ. 


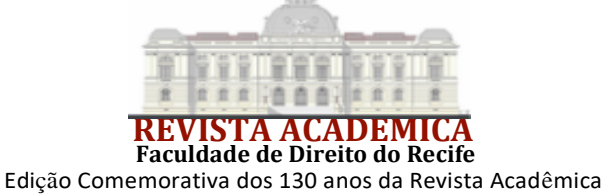

to these savings, and to obtain income from them, it is necessary to privatize social rights.

Keywords: public debts; social security reform; neoliberalism; financialization.

\section{INTRODUÇÃO}

Há uma profunda relação entre a história da dívida pública brasileira e o desenvolvimento econômico do Brasil. O endividamento externo brasileiro se inicia com a proclamação da Independência, quando em 1823 o país negociou seu primeiro empréstimo em Londres (STACHLER, p. 124). Desde então, os empréstimos contraídos pelo Brasil seriam pagos através de novos empréstimos, utilizados para o financiamento dos déficits orçamentários, pagamento dos juros e das amortizações de empréstimos anteriores.

Esse processo foi expandido significativamente durante o período da Ditadura Militar (governo juridicamente ilegal), com o intuito de financiar o "milagre econômico" (STACHLER, p. 127). Em 1964 a dívida externa brasileira era de US\$ 3,294 bilhões no final do período militar, em 1985, totalizava US\$105,171 bilhões, conforme dados da Auditoria Cidadã da Dívida (2016). Esse cenário foi duramente agravado com a política de juros aplicada pelos Estados Unidos da América no final dos anos 1970. Com o fim da paridade ouro-dólar decretada pelos Estados Unidos em 1971 houve uma emissão ilimitada de dólares no mercado financeiro, essa grande oferta de créditos influenciou o endividamento não só do Brasil, mas também dos estados brasileiros, que buscavam financiamentos para desenvolver-se.

É a partir desses processos que o Fundo Monetário Internacional e o Banco Mundial, este último principalmente através do Banco Internacional para Reconstrução e Desenvolvimento (BIRD), passam a influenciar politicamente a economia dos países latino-americanos para garantir que o pagamento da dívida externa seja devidamente pago. Em 1983 o Brasil assinou a primeira entre diversas - Cartas de Intenções com o Fundo Monetário Internacional, organismo que passou a interferir abertamente em assuntos internos do País, com repercussões na economia estaduais e municipais.

Assim, objetiva-se compreender como esse tipo de intervenção se deu, especificamente, no Estado de Pernambuco e sua possível relação com o aprofundamento de políticas neoliberais no estado, bem como os efeitos da financeirização na seara previdenciária estadual. Importa demarcar que desde o término da segunda guerra mundial o capitalismo em seu campo econômico é capitaneado pelo setor financeiro, a partir da especulação, esse setor alimenta o mecanismo de acumulação capitalista. Do ponto de vista ideológico e social, o capitalismo neoliberal atua a partir de mecanismos de construção do trabalhador-empresa e Estado-empresarial.

A cientista política norte-americana, Wendy Brown, define a financeirização como cria do neoliberalismo, sendo este um sistema caracterizado a um conjunto de políticas que "privatizam a propriedade e os serviços públicos, reduzem radicalmente o Estado social, amordaçam o trabalho, desregulam o capital e produzem um clima de impostos e tarifas amigáveis para investidores estrangeiros" (BROWN, 2019, p. 29). Nos países do sul global o neoliberalismo tem uma especificidade, as imposições pelo FMI e BM de ajustes estruturais, vinculados à reestruturação dos empréstimos e da dívida.

Uma das características de Estados tipicamente neoliberais é a prioridade em sustentar a integridade do sistema financeiro em detrimento do bem-estar da população e do meio ambiente,

MELO, Aline Araújo de Albuquerque; ESTEVES, Juliana Teixeira. NEOLIBERALISMO E O SISTEMA DA DÍVIDA: COMO A 


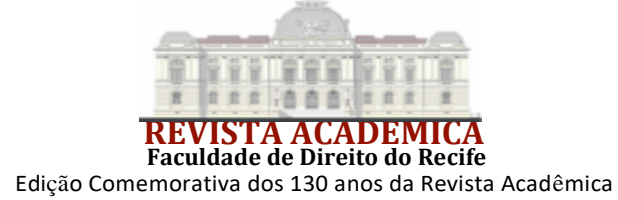

assim, as dívidas com o setor financeiro internacional geraram crises de caráter endêmico em países periféricos e o Estado foi obrigado a adaptar-se ao governo empresarial (DARDOT; LAVAL, 2010).

Nessa esteira, pretende-se analisar a Lei Complementar $n^{\circ} 423$, de 23 de dezembro de 2019, que altera a Lei Complementar $n^{\circ} 28$, de 14 de janeiro de 2000, que dispõe sobre o Sistema de Previdência Social dos Servidores do Estado de Pernambuco e sobre o regime de previdência complementar no âmbito do Estado de Pernambuco, instituído pela Lei Complementar $n^{\circ} 257$, de 19 de dezembro de 2013.

A pesquisa apresenta, portanto, como principal objetivo, analisar se há relação entre os contratos firmados pelo Estado de Pernambuco com o BIRD e reformas neoliberais na seara previdenciária estadual. Para tanto, é necessário compreender o que é a dívida pública, identificar a dívida pública interna e externa do Estado de Pernambuco e realizar um estudo crítico aprofundado sobre o sistema da dívida.

\section{LEVANTAMENTO DOS CONTRATOS DE EMPRÉSTIMO ENTRE O ESTADO DE PERNAMBUCO E O BANCO MUNDIAL}

A etapa inicialmente desenvolvida nesta pesquisa foi o levantamento das cláusulas contratuais estabelecidas para contratos firmados entre o Estado de Pernambuco e o Banco Internacional para Reconstrução e Desenvolvimento (BIRD), principal credor internacional do Estado de Pernambuco. Através do Portal de Transparência de Pernambuco, na página de despesas detalhadas, foram obtidos o número do empenho 55 empenhos realizados entre os anos de 2011 a 2020, o valor empenhado e data de cada lançamento, organizados por ano da despesa, sendo a unidade gestora a Secretaria da Fazenda do Estado de Pernambuco e o credor do empenho o BIRD. O empenho é a etapa em que o governo reserva o dinheiro que usará para pagar suas dívidas com o BIRD, uma forma de organizar os gastos referentes às dívidas públicas externas.

A partir disso, foi feito Pedido de Acesso à Informação registrado sob o $n^{\circ}$ 100896/2020 à Ouvidoria Geral do Estado, enviado posteriormente à Autoridade Administrativa da Secretaria da Fazenda (SEFAZ) solicitando acesso aos contratos firmados entre o Estado de Pernambuco e o BIRD. Em resposta, foram liberados para análise quatro documentos, são eles:

1. Contrato de Empréstimo no 8135-BR, firmado em 18 de junho de 2012, para Projeto de Inclusão Econômica Rural de Pernambuco - Projeto Pernambuco Rural Sustentável. (Pernambuco Rural Economic Inclusion).

2. Convênio de Empréstimo ${ }^{\circ}$ 8142-BR, firmado em 13 de abril de 2012, para Programa de Desenvolvimento das Políticas Públicas do Estado de Pernambuco: Expandindo Oportunidades, Melhorando a Equidade no Estado de Pernambuco (Expanding Opportunities, Enhancing Equity in the State of Pernambuco Development Policy Loan).

3. Acordo de Empréstimo no 8284-BR, firmado em 18 de julho de 2013, para Programa de Desenvolvimento das Políticas Públicas do Estado de Pernambuco(Expanding Opportunities, Enhancing Equity in the State of Pernambuco Development Policy Loan).

4. Acordo de Garantia do Empréstimo no 8284-BR (Expanding Opportunities, Enhancing Equity in the State of Pernambuco Development Policy Loan).

MELO, Aline Araújo de Albuquerque; ESTEVES, Juliana Teixeira. NEOLIBERALISMO E O SISTEMA DA DÍVIDA: COMO A 
Entretanto, os documentos fornecidos pela Secretaria da Fazenda estavam incompletos, haja vista a existência de muitos outros contratos entre o BIRD e o Estado de Pernambuco. Através do sitio web do Banco Mundial, The World Bank, pesquisando pelo termo "PERNAMBUCO" foram encontrados, ao todo, 15 (quinze) acordos de empréstimos firmados entre o Estado de Pernambuco junto ao Banco Mundial entre os anos de 1979 e 2021:

Tabela 1 - Acordos de empréstimos entre o Estado de Pernambuco e o Banco Mundial

\begin{tabular}{|c|c|c|c|c|c|}
\hline Projeto & ID & Aprovação & Encerramento & Custo total & $\begin{array}{c}\text { Última } \\
\text { modificação }\end{array}$ \\
\hline $\begin{array}{l}\text { Sites and Services } \\
\text { and Low-Cost } \\
\text { Housing Project }\end{array}$ & P006300 & 23/01/1979 & $31 / 12 / 1984$ & $\begin{array}{l}\text { US\$ } 93.00 \\
\text { milhões }\end{array}$ & N/A \\
\hline $\begin{array}{l}\text { Northeast Water } \\
\text { Supply and } \\
\text { Sewerage Project }\end{array}$ & P006302 & 30/01/1979 & $31 / 12 / 1985$ & $\begin{array}{l}\text { US\$ } \\
100.00 \\
\text { milhões }\end{array}$ & N/A \\
\hline $\begin{array}{l}\text { Pernambuco Rural } \\
\text { Development } \\
\text { Project }\end{array}$ & P006295 & 14/06/1979 & $31 / 12 / 1986$ & $\begin{array}{l}\text { US\$ } 40.00 \\
\text { milhões }\end{array}$ & N/A \\
\hline $\begin{array}{l}\text { Northeast } \\
\text { Development } \\
\text { Project } \\
\text { PERNAMBUCO }\end{array}$ & P006432 & $12 / 06 / 1986$ & 30/06/1996 & $\begin{array}{l}\text { US\$ } 92.00 \\
\text { milhões }\end{array}$ & N/A \\
\hline $\begin{array}{lr}\text { Rural } & \text { Poverty } \\
\text { Alleviation } \\
\text { Pernambuco }\end{array}$ & P04256 & $12 / 12 / 1996$ & $31 / 12 / 2001$ & $\begin{array}{l}\text { US\$ } 52.00 \\
\text { milhões }\end{array}$ & $15 / 01 / 2013$ \\
\hline $\begin{array}{l}\text { Rural Poverty } \\
\text { Reduction Project - } \\
\text { Pernambuco }\end{array}$ & P050880 & 26/06/2001 & $31 / 01 / 2010$ & $\begin{array}{l}\text { US\$ } 40.00 \\
\text { milhões }\end{array}$ & $12 / 04 / 2016$ \\
\hline $\begin{array}{l}\text { Recife Urban } \\
\text { Upgrading Project }\end{array}$ & P049265 & $24 / 06 / 2003$ & 02/03/2011 & $\begin{array}{l}\text { US\$ } 84.00 \\
\text { milhões }\end{array}$ & $15 / 01 / 2013$ \\
\hline $\begin{array}{l}\text { Pernambuco } \\
\text { Integrated } \\
\text { Development: } \\
\text { Education Quality } \\
\text { Improvement } \\
\text { Project }\end{array}$ & P069934 & $14 / 10 / 2004$ & $30 / 06 / 2010$ & $\begin{array}{l}\text { US\$ } 52.00 \\
\text { milhões }\end{array}$ & $15 / 01 / 2013$ \\
\hline $\begin{array}{l}\text { Additional } \\
\text { Financing for the } \\
\text { Rural Poverty } \\
\text { Reduction Project - } \\
\text { Pernambuco }\end{array}$ & P101879 & $19 / 10 / 2006$ & N/A & $\begin{array}{l}\text { US\$ } 40.00 \\
\text { milhões }\end{array}$ & $12 / 04 / 2016$ \\
\hline
\end{tabular}




\begin{tabular}{|c|c|c|c|c|c|}
\hline $\begin{array}{lr}\text { BR Nova Gerar } \\
\text { Carbon Finance adn } \\
\text { Solid r Waste } \\
\text { Management Project } \\
\text { II }\end{array}$ & P105389 & $03 / 12 / 2008$ & $30 / 06 / 2015$ & $\begin{array}{l}\text { US\$ } 10.00 \\
\text { milhões }\end{array}$ & $15 / 01 / 2018$ \\
\hline $\begin{array}{lr}\text { PE } & \text { SWAP } \\
\text { Pernambuco Educ } \\
\text { Results\& Account. } \\
\text { (PERA) }\end{array}$ & P106208 & $14 / 04 / 2009$ & $30 / 11 / 2015$ & $\begin{array}{l}\text { US\$ } \\
580.40 \\
\text { milhões }\end{array}$ & $23 / 03 / 2016$ \\
\hline $\begin{array}{l}\text { Leveling the Playing } \\
\text { Field for } \\
\text { Quilombola } \\
\text { Communities in } \\
\text { Northeastern Brazil }\end{array}$ & P118988 & 07/07/2009 & $30 / 07 / 2014$ & $\begin{array}{l}\text { US\$ } 1.90 \\
\text { milhões }\end{array}$ & $12 / 04 / 2016$ \\
\hline $\begin{array}{l}\text { Brazil Pernambuco } \\
\text { Sustainable Water }\end{array}$ & P108654 & $14 / 01 / 2010$ & $30 / 03 / 2020$ & $\begin{array}{l}\text { US\$ } \\
410.00 \\
\text { milhões }\end{array}$ & $30 / 04 / 2021$ \\
\hline $\begin{array}{l}\text { Pernambuco Rural } \\
\text { Economic Inclusion }\end{array}$ & P120139 & 06/03/2012 & $30 / 06 / 2020$ & $\begin{array}{l}\text { US\$ } \\
135.25 \\
\text { milhões }\end{array}$ & $05 / 05 / 2021$ \\
\hline $\begin{array}{l}\text { Expanding } \\
\text { Opportunities, } \\
\text { Enhancing Equity in } \\
\text { the State of } \\
\text { Pernambuco } \\
\text { Development Policy } \\
\text { Loan }\end{array}$ & P106753 & $22 / 03 / 2012$ & $31 / 03 / 2013$ & $\begin{array}{l}\text { US\$ } \\
500.00 \\
\text { milhões }\end{array}$ & $12 / 04 / 2016$ \\
\hline $\begin{array}{l}\text { Pernambuco Equity } \\
\text { and Inclusive } \\
\text { Growth DPL }\end{array}$ & P132768 & $25 / 06 / 2013$ & $30 / 09 / 2014$ & $\begin{array}{l}\text { US\$ } \\
550.00 \\
\text { milhões }\end{array}$ & $18 / 03 / 2016$ \\
\hline
\end{tabular}

Fonte: Banco Mundial

Inicialmente foram analisados o Acordo de Empréstimo (Loan Agreement) e o Acordo Sobre Garantias (Guarantee Agreement), a fim de compreender os termos do contrato de empréstimo. Posteriormente foram analisados o Documento do Projeto (Project Paper ou Work Paper) e Informações sobre Projeto (Project Information Document - PID), com detalhes sobre o funcionamento de cada projeto, e a Situação da Implementação e Relatório dos Resultados (Implementation Status and Results Report), que demonstra o andamento do projeto na prática. Por fim, foram estudados os Relatório sobre Avaliação do Desempenho do Projeto (Project Performance Assentment Report) e Documentos de Avaliação do Projeto (Project Appraisal Document).

Busca-se, a partir da análise dos documentos, possíveis orientações do Banco Mundial sobre o sistema de seguridade social para o estado de Pernambuco. Em cada um desses documentos analisados, foram pesquisados os termos "social security" (seguridade social) e "fund pension" 


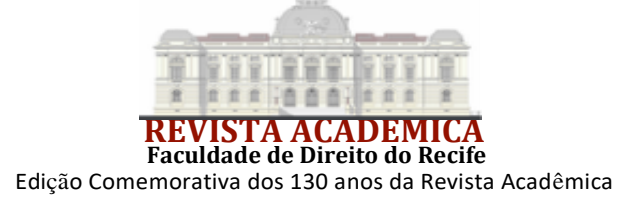

(fundo de pensão). Foram encontradas citações e críticas diretas ao sistema previdenciário local e menção à necessidade de uma reforma previdenciária em apenas um projeto, o "PE SWAP Pernambuco Educ Results\& Account. (PERA)".

\subsection{IDENTIFICAÇÃO DE TRECHOS RELEVANTES PARA ESTA PESQUISA}

O Convênio de Empréstimo no 8142-BR e do Acordo de Empréstimo no 8284-BR, ambos do projeto "Expanding Opportunities, Enhancing Equity in the State of Pernambuco Development Policy Loan", apesar de não mencionar reformas previdenciárias, solicita ao Estado de Pernambuco abertura de diálogo sobre o quadro de política macro-econômica. Os documentos citam a manutenção de um programa de gastos adequado, através de "endividamento sustentável", bem como medidas tributárias adequadas. Os termos, em resumo, tratam da melhoria da eficiência do gasto público.

O projeto "PE SWAP Pernambuco Educ Results\& Account. (PERA)" de acordo com o documento Informações sobre Projeto $n^{\circ}$ AB3447 (Project Information Document - PID) de 09/05/2008 tem por objetivo “(a) melhorar a qualidade, eficiência e equidade do público educação em Pernambuco; e (b) introduzir reformas de gestão que levarão a uma maior eficiência na utilização dos recursos públicos do GOP no setor da Educação."

No Documento de Avaliação do Projeto no 43184-BR (Project Appraisal Document), de 14/04/2009, foram encontrados os seguintes resultados:

6. Deficiencies in PSM limit Pernambuco's ability to provide quality services to
its population and to serve as a catalyst to private sector development. While
showing signs of improvement in fiscal management, Pernambuco still lacks in
efficiency, coverage and quality of basic services. A weak capacity for revenue
collection and a high share of salaries and other recurrent expenditures limit the
Government's capacity to invest. Likewise, a heavy administrative structure
combined with limited managerial capacity, have negatively affected the GOP's
ability to provide public services both effectively and efficiently.
7. In education, the SEE'S heavy administrative structure adversely affects the
efficient delivery of services. It is estimated that less than half of SEE'S personnel
is delivering education services in the classroom. This is compounded by a large
number of retired personnel-most of whom left public service in the prime
of their abilities under outdated social security provisions. These large
numbers of retirees, comprising 21,068 teachers, relative to 36,729 presently
in SEE'S payroll, constrain Pernambuco's human resource capacity and
represent a heavy drain on the State's resources. (grifos do autor)

O trecho destacado responsabiliza o grande número de funcionários aposentados pelos problemas na estrutura educacional do Estado de Pernambuco. A passagem afirma que a maioria dos professores aposentados deixaram o serviço público no auge de suas habilidades sob as disposições de previdência social desatualizadas.

No mesmo documento, o Banco Mundial faz um resumo da evolução dos ajustes fiscais no Estado de Pernambuco e insere reformas previdenciárias como ponto positivo destes ajustes. Interessante transcrever alguns trechos neste relatório:

17. From a deficit position in 2003, since 2004 Pernambuco has implemented important measures to overcome the financial disequilibrium caused by high expenditures and low revenues, such as debt restructuring, reorganization of the 


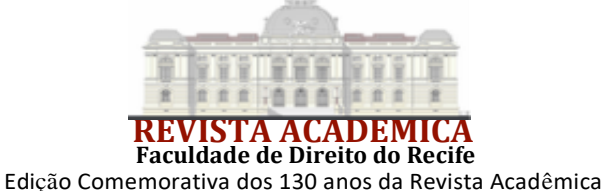

\begin{abstract}
State's social security system and restructuring of the fiscal system. (...)

45. Under the debt renegotiation Law 9496 of 1997, Pernambuco subscribed to the April 1998 contract governing the refinancing of its debt with the federal government. In accordance with its terms, the value of the operation with regard to Pernambuco amounted to R $\$ 163,641$ million or 0.5 percent of State GDP. In exchange for the rescue package, the State has committed to complying with fiscal targets and structural reform programs through rolling 3-year Fiscal Adjustment Program (PAFs).

46. The targets established in the FAP are very similar to the Fiscal Responsibility Law requirements. Besides the personnel and indebtedness indicators, the FAP comprises targets for primary surplus, own revenue collection and investment expenditures. In addition, structural reforms are also included and embrace privatization programs, social security reforms, public sector reforms, etc. The PAFs are reviewed and renewed annually by the National Treasury Secretariat (STN). (grifos do autor)
\end{abstract}

No ano de 2002 o Banco Mundial lançou relatório produzido por uma equipe em missão em Pernambuco entre os anos 1999-2000 o documento é chamado "Brazil - Growth and poverty reduction in Pernambuco, $\mathrm{n}^{\mathbf{0}}$ 20754-BR". O relatório relata um sistema de seguridade social desequilibrado e, para solucionar essas desigualdades de tratamento, seria necessária reforma previdenciária em âmbito federal. Destacamos os dois trechos desse relatório:

ES 13. To strengthen sustainability, Pernambuco's Government has successfully contained the growth of personnel expenditures, through reduction of special appointments (cargos de confianca) and restraint in wage and employment growth. With increased tax growth triggered by faster GDP growth in 2000, the Government had reduced annual personnel expenditures to $65 \%$ of net revenues by mid-2000. A reasonable target would be to reduce these costs to about $55 \%$ of net revenues (the level proposed for the 2001 budget), or about a $15 \%$ further reduction in the ratio. This will require both increased efforts to raise ICMS revenues, for example by $10 \%$ of total net revenues (or about $1 \%$ of the state's GDP), as well as efforts to deepen administrative reformn and reduce personnel costs, by say $5 \%$. With $55 \%$ of net revenues in personnel costs and a primary surplus of $15 \%-20 \%$ of net revenues to help meet debt service obligations, the Government could possibly allocate around $15 \%$ of net revenues to investment, higher than the $2 \%$ in recent years. A sustainable effort to reduce personnel expenditures will need to address the imbalance between civil service retirement benefits and retirement contributions. The new fund that is being created does not fully address this imbalance, as it only suffices to pay for the future benefits of those that are about five years away from retirement. The resolution of the imbalance lies in new social security reforms that need to be undertaken at the federal level.

(...)

ES35. Labor Policies. Labor policies are primarily federal policies. The chief labor market issues include: (i) the heavy burden of non-wage costs, particularly the impact of taxes, including the income tax (15\%), the Salario-Educaqdo (2.5\%), social security contributions (31\%), and contributions to FGTS (8\%);4 (ii) constitutional constraints on the organization of labor unions (the unicidade sindical issue), which disallows labor choice with regard to the particular form and level of union organization; (iii) the weakness of collective bargaining; (iv) the juridical weakness of labor contracts, both individual and collective; and (v) the excessive role of labor judges (the poder normativo issue), which prevents negotiation and mediation between the parts in conflict. Resolution of these issues

MELO, Aline Araújo de Albuquerque; ESTEVES, Juliana Teixeira. NEOLIBERALISMO E O SISTEMA DA DÍVIDA: COMO A 


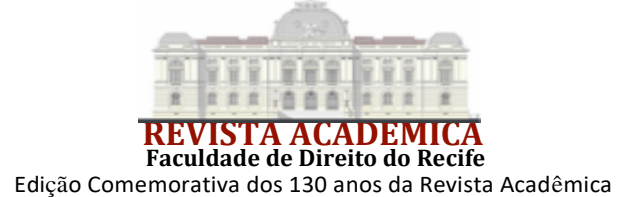

is being sought through labor reform. Measures that have been adopted to improve flexibility include the removal of wage indexation and the introduction of: profit sharing by labor, fixed term contracts, seasonal and cyclical allocation of work hours, part-time labor, and mediation in collective bargaining. (grifos do autor)

O documento aponta não somente a reforma previdenciária como uma solução para questões financeiras do Estado, mas também uma reforma trabalhista. Estas recomendações serão analisadas no tópico a seguir.

\section{DISCUSSÃO CRÍTICA}

Para início dos estudos, é importante compreender como a dívida total de um país é formada. No que se refere à origem da dívida, há duas classificações básicas, a dívida interna e a externa (MILLET; TOUSSAINT, 2006, pg. 43). A primeira é celebrada com credor nacional, em que a negociação dos títulos emitidos é feita através da moeda corrente do país, por exemplo, e dívida externa, contraída com credor internacional, utilizando moedas não correntes no país. Esta, por sua vez, é composta por dívida externa pública e dívida externa privada, quando contraída por organismos privados, cuja dívida não é garantida pelo Estado.

Já a dívida externa pública é contraída pelo próprio Estado ou por organismos cuja dívida é garantida pelo Estado de forma bilateral (por exemplo, entre dois países), multilateral (com organismos multilaterais), ou privada (com credores privados externos). As organizações multilaterais, essenciais para compreensão do objeto de pesquisa em questão, são formadas por diversos governos com a finalidade de alcançar objetivos comuns aos países membros, a exemplo do Fundo Monetário Internacional (FMI), do Banco Internacional para Reconstrução e Desenvolvimento (BIRD).

Importante frisar é que a dívida pública externa passou por uma crise, a chamada "crise da dívida”. Quando em 1971, após os Estados Unidos ajudar na reconstrução da Europa, o volume de dólares em circulação no mundo cresceu consideravelmente e, para não esgotar suas reservas, o governo norte-americano limitou a possibilidade de conversão dos dólares em ouro. Quando o ritmo de crescimento e reconstrução dos países desenvolvidos desacelerou, os bancos ocidentais estavam com dólares acumulados em seus caixas. Assim, os bancos começaram a ceder empréstimos, a juros baixos, aos países em desenvolvimento.

Todavia, a partir do início do neoliberalismo nos Estados Unidos e na Inglaterra, com Ronald Reagan e Margaret Thatcher, respectivamente, houve forte aumento das taxas de juros, a fim de atrair os capitais. Após fracassos norte-americanos no Vietnã, Irã e Nicarágua, na década de 1970, seria necessário fomentar o mercado e, para isso, Paul Volcker, diretor da Reserva Federal dos Estados Unidos, elevou unilateralmente, as taxas de juros (MILLET; TOUSSAINT, 2006, p. 62).

O que os países em desenvolvimento não esperavam é que as taxas de juros dos empréstimos variariam acompanhando a curva crescente norte-americana e inglesa. Assim, as dívidas triplicaram da noite para o dia, de cerca $5 \%$ para $18 \%$. O primeiro país a declarar publicamente que não teria condições para reembolsar a dívida foi o México, em 1982, seguido pelo Brasil e Argentina (MILLET; TOUSSAINT, 2006, p. 63).

A Constituição Federal do Brasil, em seu art. 52, estabelece que compete ao Senado Federal, privativamente "autorizar operações externas de natureza financeira, de interesse da

MELO, Aline Araújo de Albuquerque; ESTEVES, Juliana Teixeira. NEOLIBERALISMO E O SISTEMA DA DÍVIDA: COMO A 


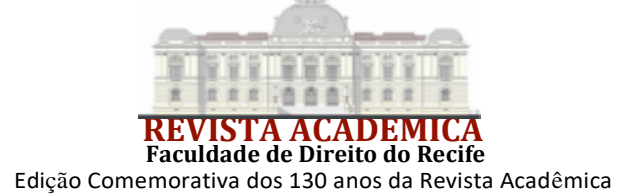

União, dos Estados, do Distrito Federal, dos Territórios e dos Municípios" (BRASIL, 1988), dentre outras atribuições relacionadas ao endividamento público.

No ano 2000 houve uma forte aceleração das operações de crédito dos estados, incluindo o Estado de Pernambuco, junto ao Banco Mundial, especialmente o BIRD. Existe uma explicação para isso, com a Lei $n^{\circ} 9.496 / 1997$ houve a implantação de um rigoroso programa de ajuste fiscal (PAF), que envolvia a renegociação das dívidas dos entes federativos brasileiros com a União, mas que elevou significativamente a dívida interna dos estados brasileiros.

O Programa de Privatização do Patrimônio Estatal (PED) e o Programa de Saneamento de Bancos (PROES), ambos associados à Lei ${ }^{\circ}$ 9.496/97, previam que os bancos estaduais fossem privatizados e seu passivo fossem somados às dívidas dos estados e considerados para renegociação, virando dívida pública. Conforme arquivos da Auditoria Cidadã da Dívida, a dívida original do Estado de Pernambuco seria de R $\$ 137.382 .613,70$ e o passivo do Banco do Estado de Pernambuco (Bandepe) no valor de R \$1.244.539.231,65 foi transformado em dívida pública após o Bandepe ter sido comprado pelo banco estrangeiro ABN Amro em 1998 (FATTORELLI, 2013).

Diante da elevada dívida dos Estados com a União e dos baixos juros oferecidos pelas organizações multilaterais, as contratações de dívidas externas, junto ao Banco Mundial e bancos privados internacionais, inicialmente se mostram menos onerosas que a obtenção de empréstimos com a própria União.

É importante destacar que, em números, o Fundo Monetário Internacional e o Banco Mundial não são os principais credores internacionais dos países subdesenvolvidos, dentre eles o Brasil. O relatório do Banco Mundial sobre a estatística internacional da dívida para o ano de 2020 mostra que os principais credores são os privados, isto é, detentores de títulos, bancos comerciais e outros credores relacionados ao comércio (WORLD BANK GROUP, 2019, p. 173).

A dívida externa do Brasil é contraída através de empréstimos por credores externos, países por exemplo, através de acordos bilaterais; com instituições financeiras multilaterais, a exemplo do FMI e do Banco Mundial; e com pessoas privadas, bancos e pessoas físicas. Todas essas dívidas são garantidas pelo Poder Público. No caso em questão, o estado de Pernambuco destina recursos de seu orçamento para pagar as dívidas contraídas com o Banco Mundial.

Nota-se que, mesmo destinando recursos orçamentários para o pagamento da dívida externa, essa dívida não acaba. Ao revés, cresce exponencialmente. Em 2018, o refinanciamento da dívida externa previsto na Lei Orçamentária Anual do Estado de Pernambuco foi de R\$ 354.500.000,00; em 2019 foi para $\mathrm{R} \$ 495.000 .000,00$; em $2020 \mathrm{R} \$ 744.950 .900,00$ e em $2021 \mathrm{R} \$$ 756.393.400,00. Esse crescente acompanha os países de baixa e média renda, que atingiu 7 trilhões 810 bilhões de dólares em 2018, mas há 10 anos atrás era de 3 trilhões 462 bilhões de dólares (WORLD BANK GROUP, 2020, p. 17).

O crescimento da dívida é agravado por políticas neoliberais tomadas ainda no governo de Fernando Henrique Cardoso, quando aprovada a Lei de Responsabilidade Fiscal (BRASIL, 2000) constando em seu art. $4^{\circ}, \S 1^{\circ}$, o tratamento da dívida pública como item do Anexo de Metas Fiscais, que integra o Projeto de Lei de Diretrizes Orçamentárias. De acordo com o Manual de Demonstrativos Fiscais, as metas fiscais "representam os resultados a serem alcançados para variáveis fiscais visando atingir os objetivos desejados pelo ente da Federação quanto à trajetória de endividamento no médio prazo" (BRASIL, 2019a, p. 61).

Ainda, o art. $4^{\circ}, \S 3^{\circ}$ do mesmo diploma legislativo aponta que "A lei de diretrizes

MELO, Aline Araújo de Albuquerque; ESTEVES, Juliana Teixeira. NEOLIBERALISMO E O SISTEMA DA DÍVIDA: COMO A

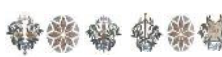




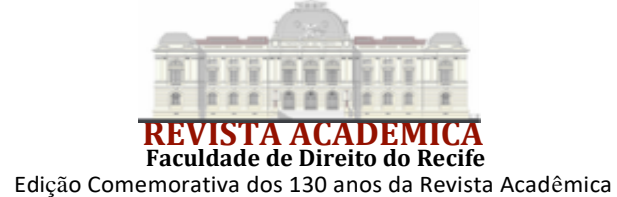

orçamentárias conterá Anexo de Riscos Fiscais, onde serão avaliados os passivos contingentes e outros riscos capazes de afetar as contas públicas, informando as providências a serem tomadas, caso se concretizem". O Manual de Demonstrativos Fiscais da Secretaria do Tesouro Nacionais conceitua riscos fiscais e obrigações fiscais. O primeiro, seriam "a possibilidade da ocorrência de eventos que venham a impactar negativamente as contas públicas [...] riscos provenientes das obrigações financeiras do governo"; e as obrigações fiscais "devem ser reconhecidas, quantificadas e planejadas como despesas na Lei Orçamentária Anual e não constituem riscos fiscais".

Ocorre que as operações de crédito, tanto interna quanto externas são tratadas pela política neoliberal como obrigações fiscais. Esta classificação segue orientação do Banco Mundial, o qual classifica os empréstimos do Tesouro Nacional como obrigações explícitas e diretas, fixadas em lei ou contrato e de ocorrência certa, previsível e baseada em fator conhecido (POLACKOVA, p. 41). Ocorre que as operações de crédito e dívidas contraídas passam por diversas variáveis, cujos efeitos são imprevisíveis. Por exemplo, a simples valorização do dólar faz crescer a dívida externa dos países. Sendo assim, é impossível definir com exatidão e antecedência os índices inflacionários, a taxa de juros e do câmbio, mesmo assim, o montante da dívida é inserido entre as metas e obrigações fiscais. Dessa forma, sem ter condições de pagar os títulos já emitidos para pagamento da dívida, o governo apenas alonga seu pagamento, emitindo novos títulos para a quitação, fazendo incidir mais juros e aumentando o nível de endividamento do país. Essa troca de uma dívida antiga por outra mais recente também ocorre a nível estadual e municipal.

É necessário que se compreenda que: se a dívida pública externa dos países subdesenvolvidos continua a aumentar, apesar do pagamento de valores vultuosos, os recursos que ingressam a título de empréstimo são menores do que aqueles que saem a título de amortização e pagamento de juros. Em suma, o rendimento do capital emprestado é maior que a produção do país devedor, sendo assim, além de permanecer devedor, esses países têm seu estoque da dívida sempre crescente. Como apontado por Millet e Toussaint (2006, p. 124), "enquanto essa lógica persistir, a dívida continuará a perpetuar-se indefinidamente, bem como o instrumento de dominação muito sutil que ela representa". Esse mecanismo de dominação Eric Toussaint (2017), na França e Maria Lúcia Fatorelli, no Brasil (2013), vão nomear de "sistema da dívida". Diante dos crescentes débitos haverá novas aquisições de empréstimos para saldar empréstimos vencidos e vincendos. Este é um círculo vicioso, um sistema que em nada beneficia os interesses sociais.

O Fundo Monetário Internacional e o Banco Mundial laçaram diversos programas ao longo dos anos para aliviar a dívida externa de países subdesenvolvidos através do perdão das dívidas. Interessante ressaltar o programa "países muito pobres muito endividados" (PPMEs) lançado em 1996 em Lyon, na França. Millet e Toussaint (2006, p. 139) apontam que: “em 2000, quatro anos após o início da iniciativa, os 42 PPMEs transferiram quantias consideráveis para o Norte: a transferência líquida sobre a dívida foi negativa para eles em cerca de US\$ 2,3 bilhões”. Houve uma redução inicial no estoque da dívida e, posteriormente, retornou ao patamar de insustentabilidade. Os autores (2006, p. 140) apresentam uma tabela na qual o FMI prevê a partir de 2002 a volta do aumento da dívida de países beneficiários do programa. A ideia, portanto, é tornar as dívidas sustentáveis, mas infinitas. Já o perdão das dívidas lançado pelo PPMEs fica condicionado à adoção de políticas econômicas recomendadas por ambas instituições, medidas alarmantemente neoliberais, como a privatização da previdência social, objeto do presente estudo.

A partir das leituras dos contratos e relatório produzidos pelo Banco Mundial e firmados com o estado de Pernambuco foram detectadas menções à reestruturação, reorganização e reforma do sistema previdenciário e da seguridade social. Essas proposições são baseadas na reivindicação de igualdade social, supressão de diferenças salariais e de tratamento, que beneficiam à uns e 


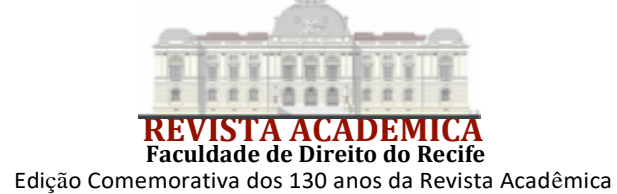

prejudicam outros. O Banco Mundial, não apenas através dos seus contratos de empréstimos, mas também por meio das diretrizes e fundamentos publicados pela instituição, tece uma série de críticas aos sistemas previdenciários públicos.

Importa mencionar o documento apresentado em 1994, intitulado "Prevenir a crise do envelhecimento: políticas para proteger as pessoas idosas e promover o crescimento" (WORLD BANK, 1994), que, nas palavras da professora Sara Granemann, "norteia a reformulação de todas as políticas sociais e chega mesmo a fundar um novo parâmetro de intervenção estatal." (GRANEMANN, 2007, p. 60). Granemann apresenta as principais críticas do Banco Mundial aos sistemas previdenciários públicos, isto é, a política redistribucionista tem sido usado para beneficiar:

a) aos ricos mais do que aos pobres. b) aos trabalhadores de "colarinho-branco ou azul" mais do que aos idosos pobres; c) aos trabalhadores urbanos mais do que aos rurais; d) aos idosos mais do que as crianças; e) aos idosos mais do que aos jovens; f) à previdência mais do que à infra-estrutura; $h$ ) à previdência mais do que à saúde e à educação. (GRANEMANN, 2007, p. 61)

Os trechos dos contratos firmados entre o Estado de Pernambuco e o Banco Mundial transcritos alhures podem dar, como primeira impressão, de que a principal preocupação do BM com relação à previdência social é o seu tratamento desigual entre trabalhadores ativos e aposentados, entre celetistas e funcionários públicos, entre os jovens e os idosos e assim por diante. O BM sustenta a busca por "igualdade social" para que seja feita uma reforma previdenciária. Assim, nos contratos e relatórios, o sistema da previdência social e o funcionalismo público aparece como responsável pela falta de investimento em políticas de interesse social (educação, saúde, etc.), desconsiderando as políticas neoliberais de corte de gastos para pagamento de dívidas públicas internas e externas, muitas delas geradas pelo próprio BM.

A Lei Complementar $n^{\circ} 423$, de 23 de dezembro de 2019, tem como principais pontos de crítica o aumento da alíquota de contribuição dos servidores de 13,5\% para 14\%, para todos os servidores, independentemente do seu salário, e cria um fundo de capitalização complementar para novos servidores, o Fundo de Aposentadorias e Pensões dos Servidores de Pernambuco (Funprev). Essencial perceber para nosso estudo que o Funprev é criado sem deixar evidenciado se será público ou se poderá vir a ser privado. Importante frisar que não há previsão na lei do formato de gestão do fundo a ser criado para gerir a previdência complementar, bem como, não há garantia de que será público, e não privado.

Em 2012 foi criado o regime complementar à previdência própria dos servidores públicos federais, com a Lei ${ }^{\circ} 12.618,30$ de abril 2012, cria o FUNPRESP, Fundação de Previdência Complementar do Servidor Público e estabelece, em seu art. $4^{\circ}, \S 1^{\circ}$, que a previdência complementar de natureza pública, com personalidade jurídica de direito privado. Todavia, a Constituição Federal, em seu art. $40, \S 15^{\circ}$ previa:

$\S 15$. O regime de previdência complementar de que trata o § 14 será instituído por lei de iniciativa do respectivo Poder Executivo, observado o disposto no art. 202 e seus parágrafos, no que couber, por intermédio de entidades fechadas de previdência complementar, de natureza pública, que oferecerão aos respectivos participantes planos de benefícios somente na modalidade de contribuição definida. (Redação dada pela Emenda Constitucional nº 41, 19.12.2003)

A caracterização da entidade de previdência complementar dos servidores públicos como

MELO, Aline Araújo de Albuquerque; ESTEVES, Juliana Teixeira. NEOLIBERALISMO E O SISTEMA DA DÍVIDA: COMO A 


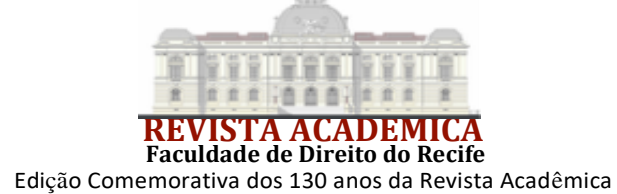

de natureza pública teve grande importância na aprovação do tema quando da votação da proposta que deu origem à Emenda Constitucional n ${ }^{\circ} 41$, de 2003 para impedir a privatização do regime de previdência dos servidores públicos, a sua entrega ao sistema financeiro. O FUNPRESP passou a ser objeto de análise do Supremo Tribunal Federal, tendo em vista a evidente inconstitucionalidade do termo "personalidade jurídica de direito privado". Todavia, a contra-reforma da previdência de 2019, Emenda Constitucional n ${ }^{0} 103$, retirou a expressão "de natureza pública", determinando que o regime de previdência complementar "será efetivado por intermédio de entidade fechada de previdência complementar ou de entidade aberta de previdência complementar."

O dinheiro da previdência é rentável e seguro, visto que é descontado mensalmente do salário dos (as) trabalhadores, mas para que o sistema financeiro tenha acesso à essa poupança, e obtenha rendimentos a partir dela, é necessário privatizar os direitos sociais. Assim, os fundos de pensão são um importante passo para o projeto de financeirização, visto que são "caixas da aposentadoria separadas das contas do empregador nas quais reservas financeiras de origem quer patronal, quer salarial (ou ambas) são acumuladas e valorizadas nos mercados financeiros." (SAUVIAT, 2005, p. 111). As críticas ao sistema previdenciário e as sugestões de reformas previdenciárias evidenciam um interesse antigo e manifesto: o capital financeiro encontrou na previdência social uma verdadeira mina de ouro.

Além das recentes alterações indicadas acima, observe-se que desde 2001 temos fortes alterações legislativas em direção ao mencionado nos documentos dos contratos de empréstimos pesquisados. Já em 2001 houve a edição das Leis complementares 108 e 109, ambas de 29 de maio de 2001 que dispuseram, respectivamente, sobre a previdência complementar dos servidores da União, Estados, Distrito Federal e Municípios, e suas respectivas autarquias, fundações e sociedade de economia mista. A outra tratou dos demais trabalhadores da iniciativa privada.

O sistema de previdência complementar foi regulamentado pelo Decreto n. 4.206, de 23 de abril de 2002, que, por sua vez, foi revogado pelo de n. 4.942, em 30 de dezembro de 2003 (para poder entrar em vigor no exercício subseqüente).O regime previdenciário do servidor público foi alterado por meio da EC n. 41, de 19 de dezembro de 2003, e trouxe uma inovação para o regime destes trabalhadores da iniciativa pública. Daí a constituição de previdências complementares fechadas para tais servidores, conforme se observa no $§ 15$ do art. 40 da CF/88 (ESTEVES, 2008).

Entre 2001 e 2005 o sistema previdenciário do município de Recife, capital de Pernambuco passou por várias reestruturações, destacando-se as ocorridas em 2005, com a criação dos fundos RECIPREV e RECIFIN. Além da criação dos dois fundos, houve a majoração das alíquotas de contribuições previdenciárias da Prefeitura (15,94\%), dos servidores, aposentados e pensionistas com proventos superiores ao teto do Regime Geral de Previdência (12,82\%).

O prefeito encaminhou à Câmara um pacote de Leis de sua iniciativa, que compreendia uma Projeto de Emenda à Lei Orgânica Municipal, um Projeto de Lei Complementar e três Projetos de Lei Ordinária, a fim de "se adequar às novas regras impostas pela Reforma da Previdência Nacional (Emenda Constitucional $\left.\mathrm{n}^{\circ} 103 / 2019\right)$, e de aumentar a capacidade de investimento do Município em saúde, educação e obras de infraestrutura nos bairros."(Castilho, Esteves, 2021)

Diversos outros exemplos podem ser mencionados, mas optou-se por manter o recorte estadual na averiguação. Ademais, o argumento do aumento da capacidade de investimento coaduna-se com os 'conselhos' existentes nas cláusulas dos contratos estrangeiros, demonstrados

MELO, Aline Araújo de Albuquerque; ESTEVES, Juliana Teixeira. NEOLIBERALISMO E O SISTEMA DA DÍVIDA: COMO A 


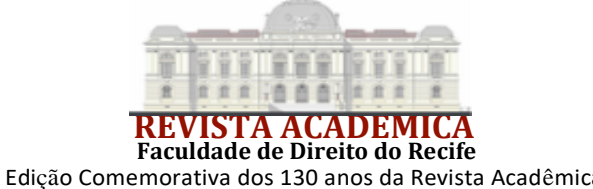

na pesquisa.

\section{CONSIDERAÇÕES FINAIS}

Analisando os documentos contratuais firmados entre o Estado de Pernambuco e o Banco Mundial foram identificadas críticas ao sistema previdenciário brasileiro e estadual, bem como sugestões sobre a necessidade de reforma previdenciária sob a justificativa de alcançar um sistema mais justo e igualitário. Todavia, o interesse do sistema financeiro na previdência dos(as) trabalhadores(as) reside no dinheiro rentável e seguro que é descontado regularmente e pode ser utilizado pelo sistema financeiro para investimentos no capital fictício ou improdutivo (DOWBOR, 2017).

Nota-se, portanto, a transformação dos direitos sociais em serviços comercializáveis, submetidos ao mercado financeiro. A partir do endividamento externo, são feitas concessões e reformas que minoram os direitos sociais para garantir o pagamento das dívidas com instituições financeiras. Na prática, a contribuição previdenciária paga pelos servidores estaduais, hoje destinada aos cofres públicos, poderá ser transferida para fundos privados de pensão. A mudança no sistema não cita os encargos com o pagamento de seus servidores atualmente inativos e pensionistas, que deverão continuar sendo pagos pelo Estado.

Ademais, como salientado por Esteves e Menezes Gomes (2020), quando instaurada a crise capitalista os fundos de pensão e previdências complementares privadas tendem a criar um cenário de incerteza ainda maior, pois estão submetidas aos riscos de mercado.

Os fundos de aposentadoria e pensão privados, em regra, estão sujeitos às oscilações dos mercados financeiros, seja renda fixa, variável, investimentos mobiliários ou outros. Sendo contas individuais o(a) servidor(a) acumula durante determinado tempo uma cota, dessa forma, quando for se aposentar, poderá escolher em quantas parcelas receberá o benefício. Por exemplo, se uma servidora se aposenta aos 65 anos de idade e escolhe receber o dinheiro que juntou em 130 parcelas, 10 anos, receberá somente até os 75 anos. Escolhendo receber mais parcelas, o valor mensal diminui. Com o aumento da expectativa de vida dos idosos brasileiros, têm-se um futuro incerto.

\section{REFERENCIAS}

AUDITORIA CIDADÃ DA DÍVIDA. A corrupção e a dívida pública no período militar (19641985). Disponível em: https://auditoriacidada.org.br/conteudo/corrupcao-e-divida-publica-noperiodo-militar-1964-1985/. Acesso em: 8 mar. 2021.

BRASIL. Constituição (1988). Constituição da República Federativa do Brasil. Brasília, DF: Senado Federal: Centro Gráfico, 1988.

BRASIL. Lei $n^{o}$ 9.496, de 11 de setembro de 1997. Disponível em: http://www.planalto.gov.br/ccivil_03/leis/19496.htm. Acesso em: 14 de ago. 2021.

BRASIL. Secretaria do Tesouro Nacional. Manual de demonstrativos fiscais: Aplicado à União e aos Estados, Distrito Federal e Municípios. 10. ed. Brasília: Secretaria do Tesouro Nacional, 2019.

BROWN, Wendy. Nas ruínas do neoliberalismo: a ascensão política antidemocrática no ocidente. São Paulo, SP: Editora Filosófica Politeia, 2019.

CASTILHO, Larissa Ximenes et Esteves, Juliana Teixeira. Contradições, gênero e o cuidado na

MELO, Aline Araújo de Albuquerque; ESTEVES, Juliana Teixeira. NEOLIBERALISMO E O SISTEMA DA DÍVIDA: COMO A 


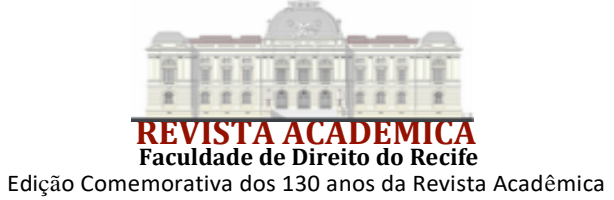

reforma da previdência do Recife (PE). Disponível em: www.brasildefato.com.br. Acesso em: 23 de nov. 2021

DARDOT, P.; LAVAL, C. A nova razão de mundo: ensaio sobre a sociedade neoliberal. São Paulo, SP: Boitempo, 2016.

DOWBOR, Ladislau. A era do capital improdutivo: a nova arquitetura do poder, sob dominação financeira,sequestro da democracia e destruição do planeta. Outras Palavras \& autonomia literária, São Paulo, 2017.

ESTEVES, Juliana Teixeira; GOMES, José Menezes. A contrarreforma da previdência, crise do capital e da previdência privada. Revista Direito e Praxis. Disponível em: https://doi.org/10.1590/2179-8966/2020/50102. Acesso em: 04 mar. 2021.

ESTEVES, Juliana Teixeira. Fundos de pensão: benefício ou prejuízo para os trabalhadores? São Paulo, SP: LTr, 2008.

FATTORELli, Maria Lúcia. Auditoria Cidadã da Dívida dos Estados. Brasília, DF: Inove Editora, 2013.

FATTORELLI, Maria Lúcia. Grécia: mecanismos do sistema da dívida corroem democracia e direitos humanos, 2016. Disponível em: https://auditoriacidada.org.br/conteudo/greciamecanismos-do-sistema-da-divida-corroem-democracia-e-direitos-humanos/. Acesso em: 20 set. 2021.

GRANEMANN, Sara. Políticas Sociais e Financeirização dos Direitos do Trabalho. Revista Em Pauta, Revista da Faculdade de Serviço Social da Universidade do Rio de Janeiro, Rio de Janeiro, n. 20, 2007.

MILLET, Damien; TOUSSAINT, Éric. 50 perguntas 50 respostas: sobre a dívida, o FMI e o Bando Mundial. Tradução de Noémie Rodrigues Josse. São Paulo, SP: Boitempo, 2006.

PERNAMBUCO. Lei Complementar $n^{o}$ 423, de 23 de dezembro de 2019. Disponível em: https://legis.alepe.pe.gov.br/texto.aspx?tiponorma $=2 \&$ numero $=423 \&$ complemento $=0 \& a n o=2019$ $\&$ tipo=\&url=. Acesso em: 26 jun. 2021.

POLACKOVA, Hana. Contingent Government Liabilities: a hidden risk for fiscal stability. Série Policy Research Working Paper n. 1989 do Banco Mundial. In: BRASIL. Secretaria do Tesouro Nacional. Manual de Demonstrativos fiscais: Aplicado à União e aos Estados, Distrito Federal e Municípios. 10. ed. Brasília: Secretaria do Tesouro Nacional, 2019.

STACHLER, Suzana Maria Garcia. Dívida externa brasileira: aspectos históricos. Revista Brasileira de Estudos Políticos.

SAUVIAT, Catherine. Os fundos de pensão e os fundos mútuos: principais atores da finança mundializada e do novo poder acionário. In: CHESNAIS, François. A finança mundializada: raízes sociais e políticas, configuração, consequências. São Paulo, SP: Boitempo, 2005.

TOUSSAINT, Éric. Pistas para alternativas. In: FATTORELLI, Maria Lúcia (org.). Auditoria da dívida externa: questão de soberania. Rio de Janeiro: Contraponto, 2003. 


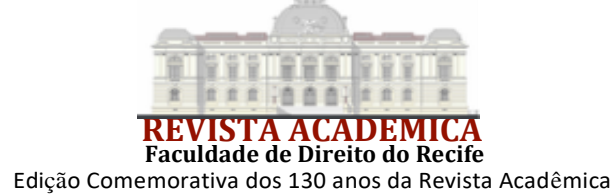

TOUSSAINT, Éric. Le système dette. Histoire des dettes souveraines et de leur répudiation. Paris, 2017.

WORLD BANK GROUP. International Debt Statistics 2020. Disponível em: https://openknowledge.worldbank.org/handle/10986/32382. Acesso em: 02 jan. 2021.

WORLD BANK GROUP. Prevenir a crise do envelhecimento: políticas para proteger as pessoas idosas e promover o crescimento, 1994.

WORLD BANK GROUP. Sites and Services and Low-Cost Housing Project. Disponível em: https://projects.worldbank.org/en/projects-operations/project-detail/P006300. Acesso em: 02 jun. 2021.

WORLD BANK GROUP. Northeast Water Supply and Sewerage Project. Disponível em: https://projects.worldbank.org/en/projects-operations/project-detail/P006302. Acesso em: 02 jun. 2021.

WORLD BANK GROUP. Pernambuco Rural Development Project. Disponível em: https://projects.worldbank.org/en/projects-operations/project-detail/P006295. Acesso em: 02 jun. 2021.

WORLD BANK GROUP. Northeast Rural Development Project (05) PERNAMBUCO. Disponível em: https://projects.worldbank.org/en/projects-operations/project-detail/P006295. Acesso em: 02 jun. 2021.

WORLD BANK GROUP. Rural Poverty Alleviation - Pernambuco. Disponível em: https://projects.worldbank.org/en/projects-operations/project-detail/P042566. Acesso em: 02 jun. 2021.

WORLD BANK GROUP. Rural Poverty Reduction Project - Pernambuco. Disponível em: https://projects.worldbank.org/pt/projects-operations/project-detail/P050880. Acesso em: 02 jun. 2021.

WORLD BANK GROUP. Recife Urban Upgrading Project. Disponível em: https://projects.worldbank.org/en/projects-operations/project-detail/P049265. Acesso em: 02 jun. 2021.

WORLD BANK GROUP. Pernambuco Integrated Development: Education Quality Improvement Project. Disponível em: https://projects.worldbank.org/en/projects-operations/projectdetail/P069934. Acesso em: 02 jun. 2021.

WORLD BANK GROUP. Additional Financing for the Rural Poverty Reduction Project Pernambuco. Disponível em: https://projects.worldbank.org/en/projects-operations/projectdetail/P101879. Acesso em: 02 jun. 2021.

WORLD BANK GROUP. BR Nova Gerar Carbon Finance adn Solid Waste Management Project II. Disponível em: https://projects.worldbank.org/en/projects-operations/project-detail/P105389. Acesso em: 02 jun. 2021.

WORLD BANK GROUP. PE SWAP Pernambuco Educ Results\& Account (PERA). Disponível em: https://projects.worldbank.org/pt/projects-operations/project-detail/P106208. Acesso em: 02 
jun. 2021.

WORLD BANK GROUP. Leveling the Playing Field for Quilombola Communities in Northeastern Brazil. Disponível em: https://projects.worldbank.org/en/projectsoperations/project-detail/P118988. Acesso em: 02 jun. 2021.

WORLD BANK GROUP. Brazil Pernambuco Sustainable Water. Disponível em: https://projects.worldbank.org/en/projects-operations/project-detail/P108654. Acesso em: 02 jun. 2021.

WORLD BANK GROUP. Pernambuco Rural Economic Inclusion. Disponível em: https://projects.worldbank.org/pt/projects-operations/project-detail/P120139. Acesso em: 02 jun. 2021.

WORLD BANK GROUP. Expanding Opportunities, Enhancing Equity in the State of Pernambuco Development Policy Loan. Disponível em: https://projects.worldbank.org/pt/projects-operations/project-detail/P106753. Acesso em: 02 jun. 2021.

WORLD BANK GROUP. Pernambuco Equity and Inclusive Growth DPL. Disponível em: https://projects.worldbank.org/pt/projects-operations/project-detail/P132768. Acesso em: 02 jun. 2021. 